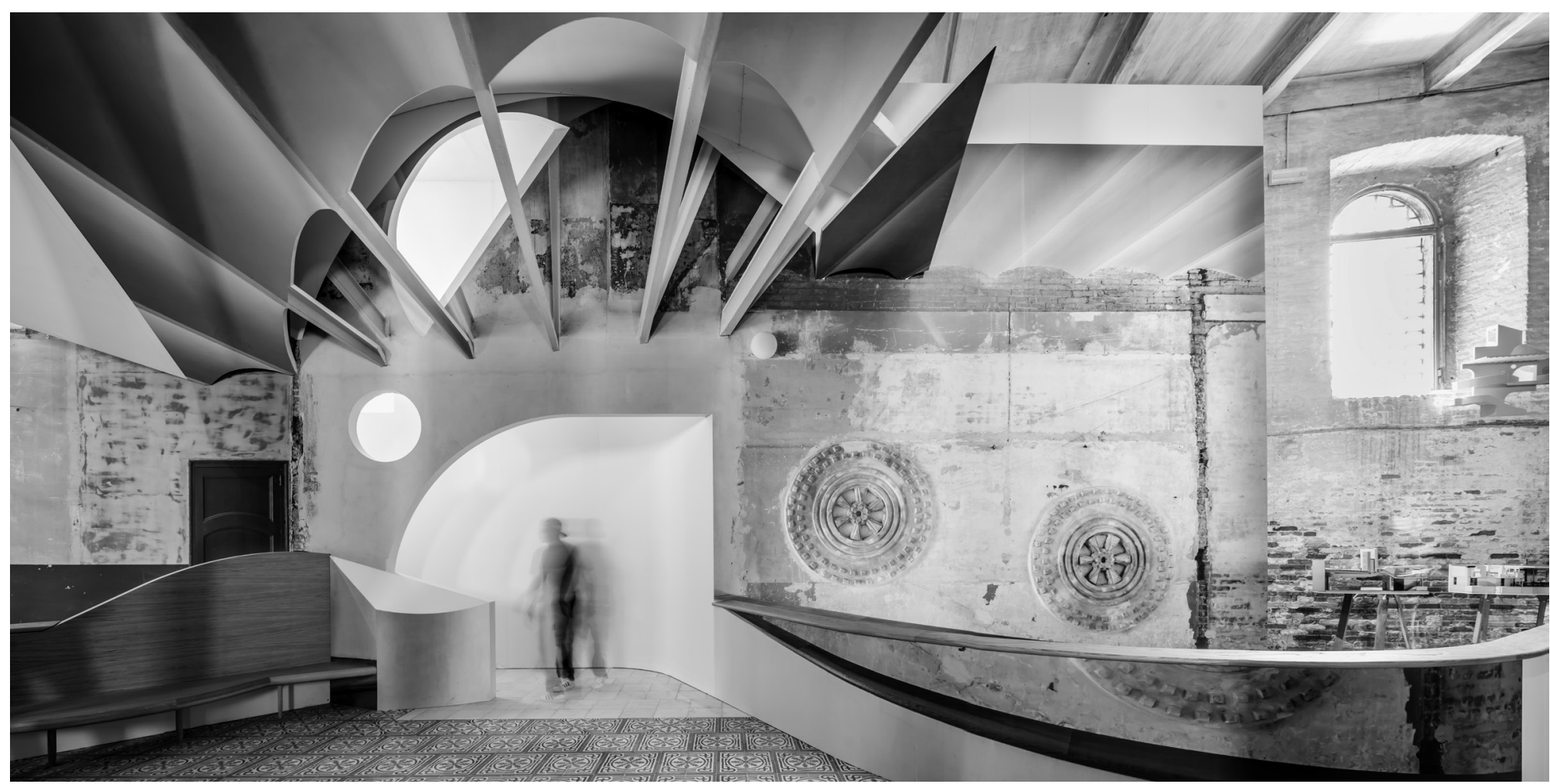

\title{
Traslados
}

\section{Del estudio al aula, de Barcelona a Venecia}

\section{Eva Prats}

Recibido 2019.09.23 ::: Aceptado 2019.09.25 DOI: $10.5821 /$ palimpsesto.20.895

Persona de contacto: studio@floresprats.com ORCID: https://orcid.org/0000-0003-3208-327X

Departamento de Proyectos Arquitectónicos de la ETSA, Universitat Politècnica de Catalunya (UPC)

nuestros estudiantes les debió resultar familiar todo el material de trabajo que encontraron al traspasar e lucernario que presentamos en la Bienal de Venecia.

Ahí había ordenados 45 metros lineales de material de proceso elaborado para el proyecto del centro de dramaturgia de la Sala Beckett en Barcelona. Metros de documentos elaborados con la responsabilidad de construir, muy parecido al material que encuentras si entras en nuestra aula de la ETSAB: todo hecho a mano, todo a la vista, las dudas, las idas y venidas... Todos pueden preguntar fácilmente: y este garabato aquí en la esquina de la hoja, ¿qué estabas probando? Y esta maqueta ia qué parte del edificio se refiere? Todas las dudas y las pruebas a la vista, en el aula, en el estudio y en la instalación para la Bienal de Venecia.

En el aula, como sucede en nuestro estudio, cada proyecto hace aparecer y desarrollar unos intereses que lo ayudan a avanzar y que van más allá que la solución específica, más allá de las circunstancias concretas, de la urgencia del encargo. Esto permite desarrollar unos temas a larga distancia, donde cada proyecto fija una reflexión que tendrá un eco en el próximo. En elau reflexión que tendrá un eco en el próximo. En el aula aproximarlas a os estudiantes con un ejercicio donde poder compartir y contrastar otras maneras posibles de interpretarlas $y$ actuar.

La pieza diseñada para la Bienal tenía dos lados; si estabas en uno no podías ver el otro. La relación entre dos lados tan diferentes la hacía cada uno al final de la visita.

Uno de los lados ya lo hemos explicado, era el que dejaba a la vista los restos del trabajo de un estudio de arquitectura que trabaja manualmente. A su vez, el material que ahí se disponía (de observación, de tanteo, de duda, de experimentación), explicaba la construcción de nuestra actitud al haber trabajado con un edificio existente, que encontramos casi en ruinas, una relacion que desconocíamos al principio y que se fue definiendo con el aprendizaje, con la experiencia de dibujar y luego construir el proyecto.
El tema del re-uso de edificios, su adaptación para acoger nuevos programas es uno de los temas que nos preocupan y fascinan a la vez, y lo hemos llevado a las aulas de la Etsab y otras escuelas donde hacemos clases durante estos últimos años. Nos pareció que era un buen momento para mostrarlo en este gigantesco escaparte que es la bienal de Arquitectura de Venecia, donde cada participante, además de responder al manifesto de los comisarios de la Bienal, lleva temas de reflexión propios para compartirlos en un campo de debate internacional.

Si pasamos a mirar la pieza desde el otro lado, la distancia que tenemos que tomar con ella es distinta, necesitamos separarnos, verla de lejos. Este es el lado que primero te encuentras al pasear por el interior del enorme edifico de Le Corderie y está a escala con el ritmo de anchas columnas de seis metros de altura que se repiten cada 6 metros.

Desde aquí la pieza responde, con un golpe de vista, a la pregunta enunciada por Grafton, las arquitectas irlandesas comisarias de la bienal, en su manifesto Freespace. En él planteaban a todos los participantes invitados a hablar de la generosidad en la arquitectura, de la capacidad que tiene cualquier proyecto de ofrecer algo más, de regalar algo, en proyecto de ofrecer algo más, de regalar algo, en lugar de limitarse tan sólo a cumplir con el prog extrapolaba a la generosidad de la naturaleza y el uso que hacen los arquitectos de la luz natural, la lluvia, la gravedad. En unas notas al final del manifesto se pedía a los participantes que propusier se pedia a los participantes que propusieran una pudieran experimentar la propuesta de manera más intuitiva, y que a su vez éstas ayudaran a intensifica las cualidades espaciales de los antiguos edificios donde se celebra La Biennale.

Como respuesta a su pregunta decidimos tratar el tema de la luz natural, con la que hemos trabajado como un material de construcción más, pero que tiene la capacidad de dar calidad a todos los demás materiales. Repasamos nuestros proyectos construidos para decidirnos por un lucernario y elegimos el último que habíamos diseñado para la nueva sede de la sala Beckett, un centro de dramaturgia en el barrio de Poblenou de Barcelona. Pensamos en reconstruirlo a escala real en Venecia y hacerlo funcionar con la luz veneciana.

En la adaptación para construir esa pieza de Barcelona en Venecia entraban en juego diversas limitaciones: a primera era la diferencia en la fuente de luz natural, que en Barcelona nos llega vertical, es fuerte como una ducha y en Venecia estábamos dentro de un edificio enorme y la luz nos llegaría por sus ventanas. El edificio de Le Corderie y el lucernario de la Beckett tenían que coordinarse para hacer trabajar la luz natural en condiciones tan diversas. Decidimos atrapar toda la condiciones tan diversas. Decidimos atrapar toda la luz que entraba por dos de las enormes ventanas del ediciciciendola con un embudo hacia el de Venecia, conduciéndola con un embudo hacia el nuevo lucernario. A esta pieza la llamamos Luz Líquida,
pues trabajaría direccionando la luz natural hasta el punto donde nos interesaba, manipulándola como si fuera agua.

Además las alturas del lucernario de la Sala Beckett y la altura de Le Corderie coincidían, ambas tenían 6 metros, el lucernario casi no cabía bajo el techo de hormigón ye acercaba a las enomes coll hormigón y se acercaba a las enormes columnas del edificio renacentista. Esta situacion era interesante, as que el nuevo lucernario rodeó la base de una columna
con un banco y el capitel de otra con la fotografía de los revoltones del techo de Barcelona.

Los dos lados de la instalación constituían dos exposiciones en una, dos traslados simultáneos: el de un fragmento de un edificio de Barcelona y el de un fragmento de nuestro estudio. A escala real se mostraban dos situaciones complementarias: el trabajo lento que desarrolla el arquitecto en su estudio para poder definir y construir, algo que se presentaba al otro lado. El lucernario fabricado con ampliaciones fotográficas pegadas a un bastidor de madera era una escenografía que quería ser un edificio, la gente podía entrar en ella, estaba iluminada por luz natural como un edificio real, ofrecía bancos donde descansar un rato de los kilómetros de exposición... Observando la pieza acabada, así de repente, se nos planteó una nueva cuestión: ¿cuánto de teatral tiene el lucernario construido en Barcelona y cuánto de edificio tenía esta replica temporal en Venecia?

EVA PRATS es Doctora Arquitecta por el RMIT Melbourne y Profesora Asociada del Departamento de Proyectos Arquitectónicos de la ETSAB, Universidad Politécnica de Catalunya (UPC). Es también Profesora de Urbanismo en el RMIT y de Proyectos en la ETH-Zúrich. 